\title{
NDVI Dynamics and Its Response to Climate Change and Reforestation in Northern China
}

\author{
Xingna Lin ${ }^{1}$, Jianzhi Niu ${ }^{1, *}$, Ronny Berndtsson ${ }^{2}$, Xinxiao Yu ${ }^{1}$, Linus Zhang ${ }^{2}$ \\ and Xiongwen Chen ${ }^{3}$ \\ 1 Key Laboratory of State Forestry Administration on Soil and Water Conservation, \\ Beijing Engineering Research Center of Soil and Water Conservation, \\ Engineering Research Centre of Forestry Ecological Engineering, Ministry of Education, \\ School of Soil and Water Conservation, Beijing Forestry University, Beijing 100083, China; \\ linxingna@bjfu.edu.cn (X.L.); Yuxinxiao@bjfu.edu.cn (X.Y.) \\ 2 Division of Water Resources Engineering \& Center for Middle Eastern Studies, Lund University, \\ P.O. Box 118, SE-221 00 Lund, Sweden; ronny.berndtsson@tvrl.lth.se (R.B.); Linus.zhang@tvrl.lth.se (L.Z.) \\ ${ }_{3}$ Department of Biological and Environmental Sciences, Alabama A\&M University, Normal, AL 35762, USA; \\ xiongwen.chen@aamu.edu \\ * Correspondence: nexk@bjfu.edu.cn; Tel.: +86-10-5168-7338
}

Received: 28 September 2020; Accepted: 14 December 2020; Published: 17 December 2020

\begin{abstract}
Vegetation is an important component of the terrestrial ecosystem that plays an essential role in the exchange of water and energy in climate and biogeochemical cycles. This study investigated the spatiotemporal variation of normalized difference vegetation index (NDVI) in northern China using the GIMMS-MODIS NDVI during 1982-2018. We explored the dominant drivers of NDVI change using regression analyses. Results show that the regional average NDVI for northern China increased at a rate of 0.001 year $^{-1}$. NDVI improved and degraded area corresponded to $36.1 \%$ and $9.7 \%$ of the total investigated area, respectively. Climate drivers were responsible for NDVI change in $46.2 \%$ of the study area, and the regional average NDVI trend in the region where the dominant drivers were temperature $(\mathrm{T})$, precipitation $(\mathrm{P})$, and the combination of precipitation and temperature (P\&T), increased at a rate of $0.0028,0.0027$, and 0.0056 year $^{-1}$, respectively. We conclude that $\mathrm{P}$ has positive dominant effects on NDVI in the subregion VIAiia, VIAiic, VIAiib, VIAib of temperate grassland region, and VIIBiia of temperate desert region in northern China. T has positive dominant effects on NDVI in the alpine vegetation region of Qinghai Tibet Plateau. NDVI is negatively dominated by $\mathrm{T}$ in the subregion VIIBiib, VIIBib, VIIAi, and VIIBi of temperate desert regions. Human activities affect NDVI directly by reforestation, especially in Shaanxi, Shanxi, and Hebei provinces.
\end{abstract}

Keywords: NDVI; climate driver; reforestation area

\section{Introduction}

Vegetation is an important component of terrestrial ecosystems [1] that plays an essential role in the exchange of water and energy, biogeochemical cycles [2], climate conditions, and carbon sequestration by linking soil, atmosphere, and water [3]. In the process of global warming, monitoring of vegetation and its driving factors are important for a better understanding of global change ecology $[4,5]$. For large-scale monitoring of vegetation, remote sensing images have been utilized widely. The normalized difference vegetation index (NDVI), derived from GIMMS or MODIS, is utilized widely to study vegetation dynamics due to its high correlation with photosynthetic capacity, leaf area index, biomass, and net primary productivity [6]. Annual and 
seasonal NDVI dynamics have been studied to detect vegetation dynamics globally and regionally [1]. Driving factors of vegetation/NDVI dynamics include climate factors, such as climate change, and human activities, such as reforestation [7].

Many researchers have studied the response of vegetation coverage to climate change and human activities at different spatial and temporal scales based on NDVI time series [8-10]. Eastman et al. indicated that NDVI has increased significantly on all continents (except Oceania) [11], and this change is assumed to be a result of global warming [12]. With global warming, the air is getting warmer and precipitation is changing. Thus, temperature and precipitation are two most important climate drivers of NDVI change $[7,13,14]$. However, these relationships vary depending on spatial location. Temperature is more effective than precipitation in humid and cold temperate regions [15]. Examples of such areas are China's northeastern permafrost zone [16], and the upper catchments of the Yellow River [17]. Usually, higher precipitation leads to higher NDVI in arid and semiarid areas such as Central Asia, southern Sahara, South Africa, Australia, and South America [18]. Similarly, precipitation has a strong influence on NDVI change in the northern Loess Plateau and the grassland in Xinjiang [19]. However, the mechanisms of NDVI response to climate change are uncertain [1], and few scholars have investigated the joint action of precipitation and temperature variability on NDVI change.

Human activities have important effects on NDVI. Wang et al. indicated that carefully planned human interaction can maximize the benefits of ecological restoration programs and minimize the effects of extreme weather [20]. Wang et al. found that reforestation can effectively increase NDVI [14]. Li et al. illustrated an almost linear relationship between reforestation area and NDVI time series increase [7]. The Natural Forest Protection Program in China has had positive effects on NDVI in areas where forestland suffered significant decline before 2000 [16]. Urbanization tends to destroy vegetation cover within the developed and surrounding areas. However, the interaction between climate change and human activity has not been considered, and the contribution of climate change and human activities to NDVI change is not clear. Therefore, it is essential to conduct regional scale research to improve the understanding of joint effects of climate change and human activity on NDVI change.

Being an important part in the global ecological environment, northern China is facing serious desertification [21], problems with sandstorms [22], and water scarcity [23] (Figure 1). To protect land resources, improve ecological environment, and ensure human security, a series of policies and measures at national level have been implemented in the area [16,24]. Improving vegetation coverage is one of these important methods. Thus, the objectives of this research were to (1) assess the spatiotemporal variation of NDVI in northern China from 1982 to 2018; (2) explore the dominant drivers of NDVI change for different climate and vegetation types; (3) improve the understanding on how climate change and human activities have affected the NDVI dynamics.

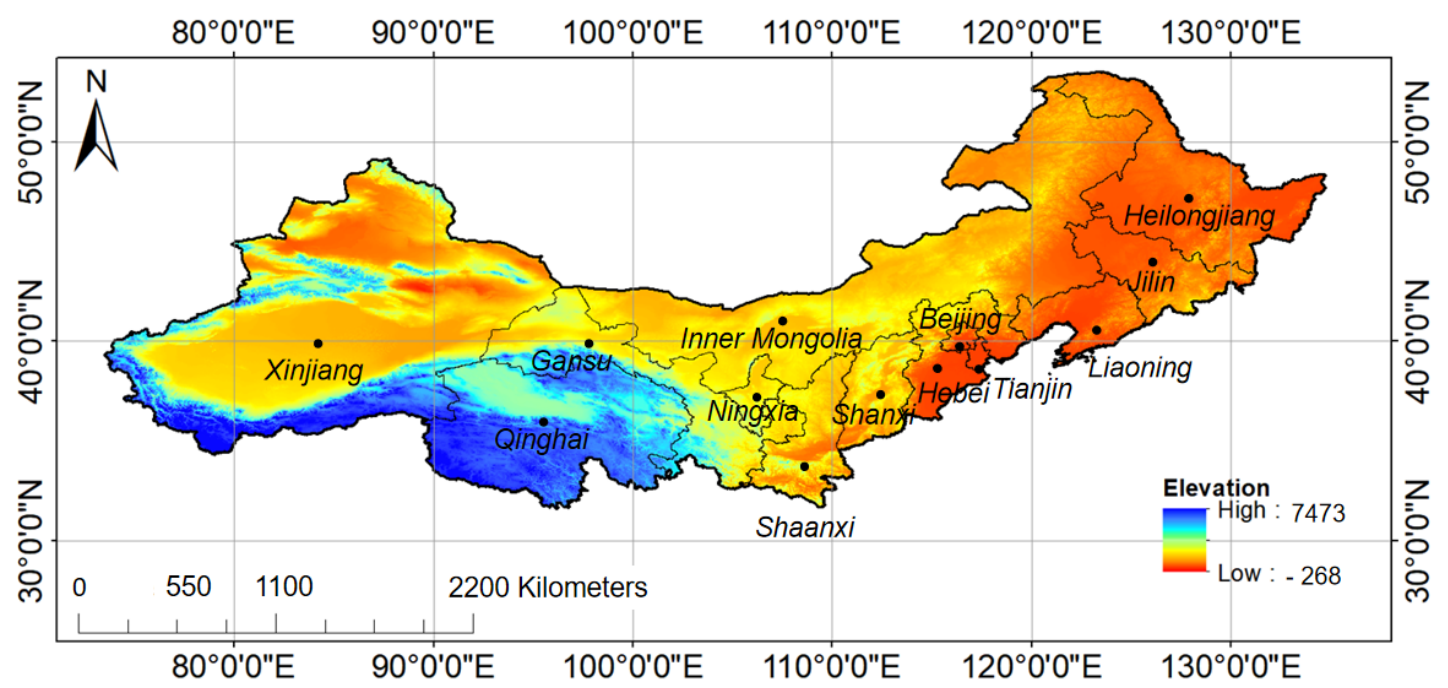

Figure 1. Study area and elevation. 


\section{Materials and Methods}

\subsection{Data Sources}

This study combined GIMMS-NDVI and MODIS-NDVI data for the period 1982-2018. The GIMMS-NDVI data set at a spatial resolution of $8 \times 8 \mathrm{~km}$ at a 15-day interval for the period of 19822006 were provided by Environmental and Ecological Science Data Center for West China (http://data.tpdc.ac.cn/zh-hans/data/1cad1a63-ca8d-431a-b2b2-45d9916d860d/?q=GIMMS), National Natural Science Foundation of China. MODIS-NDVI data were obtained from NASA's Earth Observing System MOD13Q series for the period 2000-2018 at a spatial resolution of $250 \times 250 \mathrm{~m}$ and at a 15-day interval (https://ladsweb.modaps.eosdis.nasa.gov/). Both GIMMS and MODIS datasets were processed, including the radiometric calibration of the original channels and their geometric and atmospheric corrections. Monthly NDVI was calculated using the maximum composite (MVC) method, which minimizes the following: atmospheric effects, scan angle effects, cloud contamination, and solar zenith angle effects. Annual NDVI comprised the maximum of monthly NDVI datasets. Since GIMMS and MODIS datasets are derived from different sensors, there is a need to test the consistency between them. The annual MODIS-NDVI data were resampled from $250 \mathrm{~m}$ - to $8 \mathrm{~km}$-resolution to match the resolution of annual GIMMS-NDVI data. Construction of the complete time series of NDVI at a spatial resolution of $8 \times 8 \mathrm{~km}$ from 1982 to 2018 followed the method of Xin et al. with ArcGIS 10.2 [25]. A pixel-wise linear regression was done with the annual GIMMS-NDVI and MODIS-NDVI in northern China for the overlapping period (2000-2006) [19,25]. According Figure 2, GIMMS-NDVI is linearly related to MODIS-NDVI, and the regression equation is: $\mathrm{y}=0.9943 \mathrm{x}+0.0024$.

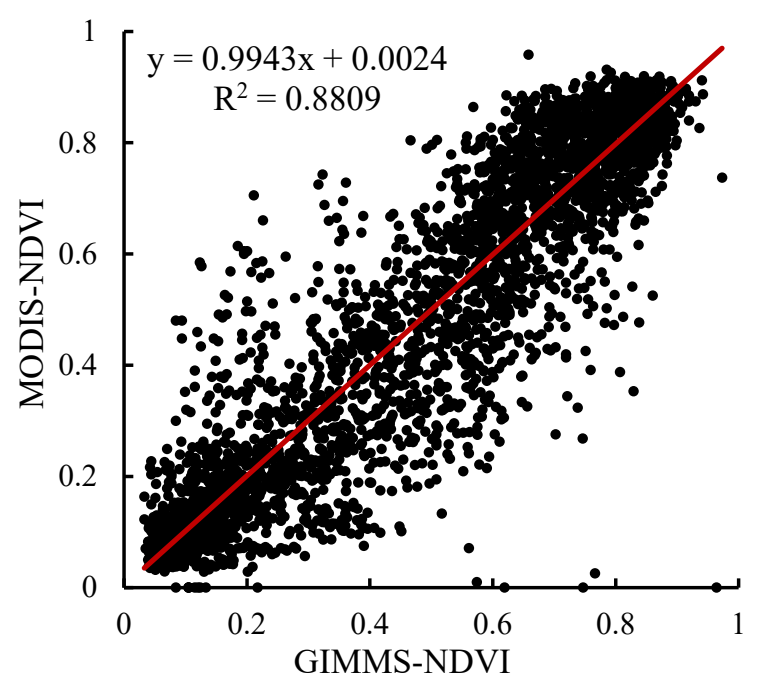

Figure 2. Relationship between GIMMS-NDVI and MODIS-NDVI ( $y$-axis is MODIS-NDVI; $x$-axis is GIMMS-NDVI).

The climatic datasets, consisting of monthly mean temperatures and precipitation, were obtained from the Chinese National Meteorological Center (http://data.cma.cn/site/index.html). They covered more than 200 meteorological stations in northern China for the period 1960-2018. ArcGIS software was used to prepare the map of precipitation and temperature distribution with spatial resolution of $8 \mathrm{~km}$ in China by kriging. Annual total precipitation $(\mathrm{mm})$ and annual average temperature $\left({ }^{\circ} \mathrm{C}\right)$ from 1982 to 2018 were calculated using monthly precipitation and temperature data. The land use data set (CNLUCC) and the vegetation regionalization were provided by Data Center of Resources and Environment Science, Chinese Academy of Sciences (http://www.resdc.cn/).

The reforestation data of northern China provinces were compiled from China statistical yearbooks and Chinese rural and environmental statistical year books. 


\subsection{Methods}

\subsubsection{Trend Analysis of NDVI, Precipitation, and Temperature}

We used the slope $(S)$ of linear regression between NDVI/precipitation/temperature (dependent variable) and year (independent variable) to quantify the trend of NDVI, precipitation, and temperature of the study area from 1982 to 2018 according to Ning et al. [1]:

$$
S=\frac{n \times \sum_{i=1}^{n}\left(i \times N_{i}\right)-\left(\sum_{i=1}^{n} i\right)\left(\sum_{i=1}^{n} N_{i}\right)}{n \times \sum_{i=1}^{n} i^{2}-\left(\sum_{i=1}^{n} i\right)^{2}}
$$

where $n$ is the number of years (37), $N_{i}$ is NDVI/precipitation/temperature in year $i$. The $t$-test was used to test whether the trend is statistically significant or not.

\subsubsection{Driver Analysis}

We considered four dominant drivers of NDVI change, which were single drivers, including precipitation $(\mathrm{P})$ and temperature $(\mathrm{T})$, a combination of precipitation and temperature $(\mathrm{P} \& \mathrm{~T})$, and other factors $(\mathrm{N})$. The single drivers were determined by partial correlation coefficients described by Equations (2) and (3) [26-29]. The combination of drivers was determined by multiple correlation coefficients described by Equations (2) and (4) [28,30]. Statistical significance of all correlation coefficients in the study was based on Student's t-test described by Equation (5) [28] and significance level was set to 0.05 . The NDVI drivers of northern China were analyzed according to Table 1, following Wang et al. [30].

$$
\begin{gathered}
r_{x y}=\frac{\sum_{i=1}^{n}\left(x_{i}-\bar{x}\right)\left(y_{i}-\bar{y}\right)}{\sqrt{\sum_{i=1}^{n}\left(x_{i}-\bar{x}\right)^{2} \sum_{i=1}^{n}\left(y_{i}-\bar{y}\right)^{2}}} \\
r_{x y, z}=\frac{r_{x y}-r_{x z} r_{y z}}{\sqrt{\left(1-r_{x z}^{2}\right)\left(1-r_{y z}^{2}\right)}} \\
r_{x, y z}=\sqrt{1-\left(1-r_{x y}^{2}\right)\left(1-r_{x z, y}^{2}\right)} \\
t_{x, y z}=\frac{r_{x, y z}}{\sqrt{1-r_{x, y z}^{2}}} \sqrt{n-m-1} \quad t_{x y, z}=\frac{r_{x y, z}}{\sqrt{1-r_{x y, z}^{2}}} \sqrt{n-m-1}
\end{gathered}
$$

where $r_{x y}, r_{x z}, r_{y z}$ are the correlation coefficients between $x$ and $y, x$ and $z, y$ and $z$, respectively; $\bar{x}$ and $\bar{y}$ are the average of $x$ and $y$, respectively; $r_{x y, z}$ is the partial correlation coefficients between $x$ and $y$, excluding the influence of $z$ on $x$ and $y ; r_{x, y z}$ is the multiple correlation coefficients between $x, y$, and $z$, in which $x$ is dependent variable, $y$ and $z$ are independent variables; $m$ is the number of independent variables ( $m=2$ in the study); $n$ is the number of samples ( $n=37$ in the study). The $r_{N T, P}$ was calculated to test the partial correlation coefficients between NDVI and temperature (T), excluding the influence of precipitation $(\mathrm{P}) ; r_{N P, T}$ represents the partial correlation coefficients between NDVI and $\mathrm{P}$, excluding the influence of $\mathrm{T} ; r_{N, P T}$ represents the multiple correlation coefficients between NDVI, $\mathrm{P}$, and $\mathrm{T}$. 
Table 1. The basis of regionalization for the dominant drivers of NDVI change in northern China $\left(t_{N T, P}\right.$ is the test statistic of the partial correlation coefficients between NDVI and temperature, excluding the influence of precipitation on NDVI; $t_{N P, T}$ is the test statistic of the partial correlation coefficients between NDVI and precipitation, excluding the influence of temperature on NDVI; $t_{N, P T}$ is the test statistic of multiple correlation coefficients between NDVI, precipitation, and temperature; to.05 is the critical value of the test statistic at a 0.05 significance level).

\begin{tabular}{cc}
\hline Dominant Driver of NDVI Change & Basis \\
\hline Temperature $(\mathrm{T})$ & $t_{N, P T}>t_{0.05}$ and $t_{N T, P}>t_{0.05}$ \\
Precipitation $(\mathrm{P})$ & $t_{N, P T}>t_{0.05}$ and $t_{N P, T}>t_{0.05}$ \\
Precipitation and temperature $(\mathrm{P} \& \mathrm{~T}) t_{N, P T}>t_{0.05}$ and $t_{N T, P}<t_{0.05}$ and $t_{N P, T}<t_{0.05}$ \\
Other factor $(\mathrm{N})$ & $t_{N, P T}<t_{0.05}$ \\
\hline
\end{tabular}

\section{Results and Discussion}

\subsection{Spatiotemporal Variation of NDVI}

During the period 1982-2018, the regional average annual NDVI for the whole northern China fluctuated between 0.392 and 0.463 , and it increased at a rate of 0.001 year $^{-1}$. The increasing rate was less pronounced (0.0007 year-1) for the Three-North Shelter Forest from 1982 to 2006 [20] and Xinjiang (0.0004 year-1) from 1982 to 2012 [31]. However, it was much lower than the average annual increase of 0.0117 year $^{-1}$ for the Shaanxi-Gansu-Ningxia region from 2000 to 2014 [7]. The reasons for these differences are complex. One possible explanation is differences in regional climate change. The mean annual precipitation did not change significantly for northern China (Figure 3), but it increased in Xinjiang (at a rate of $1.35 \mathrm{~mm}^{-1} \mathrm{yer}^{-1}$ ) [31] and Shaanxi-Gansu-Ningxia region (at a rate of $5.9 \mathrm{~mm} \mathrm{year}^{-1}$ ) [7]. The increase of precipitation supports vegetation growth by increasing soil moisture and air humidity. However, higher temperature may decrease the effect of precipitation on vegetation growth by increasing the evaporation. The average annual temperature in the investigated area increased at a rate of $0.04{ }^{\circ} \mathrm{C} /$ year, which is lower than that of Xinjiang $\left(0.06{ }^{\circ} \mathrm{C} /\right.$ year $)$ [31]. However, Shaanxi-Gansu-Ningxia region faced a decreasing mean annual temperature of $0.01{ }^{\circ} \mathrm{C} /$ year. Another reason is different human activities and land uses. In Xinjiang and Three-North Shelter Forest area, the partly reforested desert is delimited by restricted water use. As well, irrigation of forest and cropland leads to increased vegetation growth.

Based on the trend analysis, the NDVI change was divided into seven levels according to the slope between NDVI and year, and the result of $t$-test. These are serious degradation, moderate degradation, light degradation, unchanged, light improvement, moderate improvement, strong improvement (Table 2). The NDVI change for northern China is shown in Figure 4.

As seen from Figure 4, NDVI increased significantly during the investigated period. About $18.1 \%, 15.3 \%$, and $2.7 \%$ of the total area corresponded to light, moderate, and strong improvement of NDVI, respectively, from 1982 to 2018. Areas with serious, moderate, and light degradation of NDVI accounted for $0.6 \%, 1.6 \%$, and $7.5 \%$ of the total area of northern China. The region where NDVI increased is mainly distributed to the east and south of the study area, including most areas of Heilongjiang, Jilin, Liaoning, Hebei, Beijing, Tianjin, Shanxi, Shaanxi, and some parts of Gansu, Ningxia, Qinghai, and Xinjiang. Shaanxi and Shanxi Province had the largest and second largest increase in NDVI (0.0059 and 0.0052 year $^{-1}$, respectively). The area where NDVI increased in Shaanxi and Shanxi accounted for $85.1 \%$ and $75.0 \%$ of the total province area, respectively. In northeastern China, the average regional increase was between 0.0040 and 0.0045 , and NDVI increased in more than $60 \%$ of the total area. 
Table 2. Utilized statistical significance levels for NDVI change from 1980 to 2018 ( $S$ is trend of NDVI change; $t$ is the test statistic; $t .05$ is the critical value of the test statistic at a 0.05 significance level).

\begin{tabular}{lccc}
\hline & NDVI & $S$ & $t$ \\
\hline & Serious & $S \leq-0.010$ & \\
Degradation & Moderate & $-0.010 \leq S \leq-0.006$ & $t>t_{0.05}$ \\
& Light & $-0.006 \leq S \leq-0.002$ & \\
\hline No change & \multicolumn{2}{c}{$-0.002 \leq S \leq 0.002$ or $t<t_{0.05}$} & \\
\hline \multirow{3}{*}{ Improvement } & Light & $0.002 \leq S \leq 0.006$ & \\
& Moderate & $0.006 \leq S \leq 0.010$ & $t>t_{0.05}$ \\
& Strong & $S \geq 0.010$ & \\
\hline
\end{tabular}

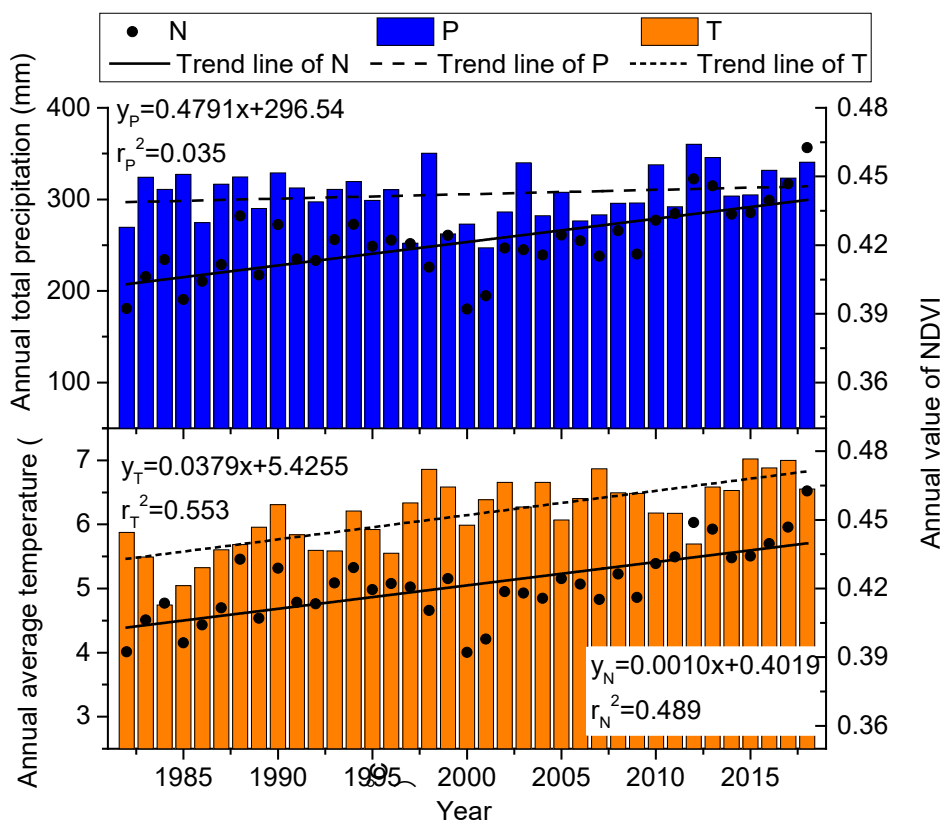

Figure 3. Variation in regional average annual NDVI (N), annual total precipitation $(\mathrm{P})$, and annual average temperature (T) for northern China from 1982 to 2018.

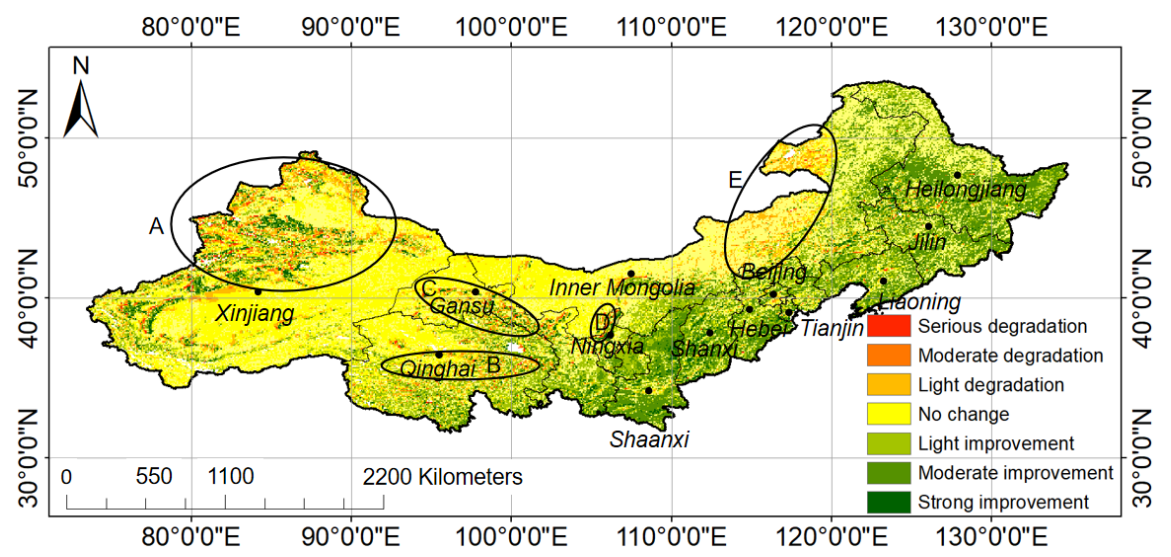

Figure 4. Change of NDVI from 1982 to 2018. (Regions A, B, C, D, and E are regions with degraded NDVI).

The degraded areas are mainly distributed in arid and semiarid regions, including northern Xinjiang Province (zone A), central east Qinghai Province (zone B), western Gansu Province (zone C), northwestern Ningxia Province (zone D), and east Inner Mongolia (zone E). Xinjiang and Qinghai Province had $14.3 \%$ and $12.0 \%$ of the area suffering degradation of NDVI, respectively. In 
Inner Mongolia, Ningxia province, and Gansu province, NDVI degraded in more than $9 \%$ of the area. Beijing and Tianjian experienced degraded NDVI area corresponding to $8.5 \%$ and $9.3 \%$, respectively.

\subsection{Response of NDVI Change to Climate Change}

We analyzed the dominant drivers for NDVI change in northern China such as precipitation $(\mathrm{P})$, temperature $(\mathrm{T})$, precipitation and temperature $(\mathrm{P} \& \mathrm{~T})$, and other factors $(\mathrm{N})$, according to the results of driver analysis described in Table 1 (Figure 5). Climatic factors (P, T, P\&T) drove NDVI change among $46.2 \%$ of the total area of northern China. The area that is driven by precipitation, temperature, and a combination of precipitation and temperature accounted for $14.4 \%, 20.2 \%$, and $11.6 \%$, respectively. Thus, temperature appears to be the most important NDVI driver. Figure 5 shows that the zone of the precipitation driver is mainly distributed in the middle northern China, including parts of Inner Mongolia, Ningxia, Shaanxi, and the northwest of Hebei province. Precipitation and temperature are not the main drivers for NDVI change in the other $53.8 \%$ of northern China. This area corresponds to northeastern and part of northwestern China.

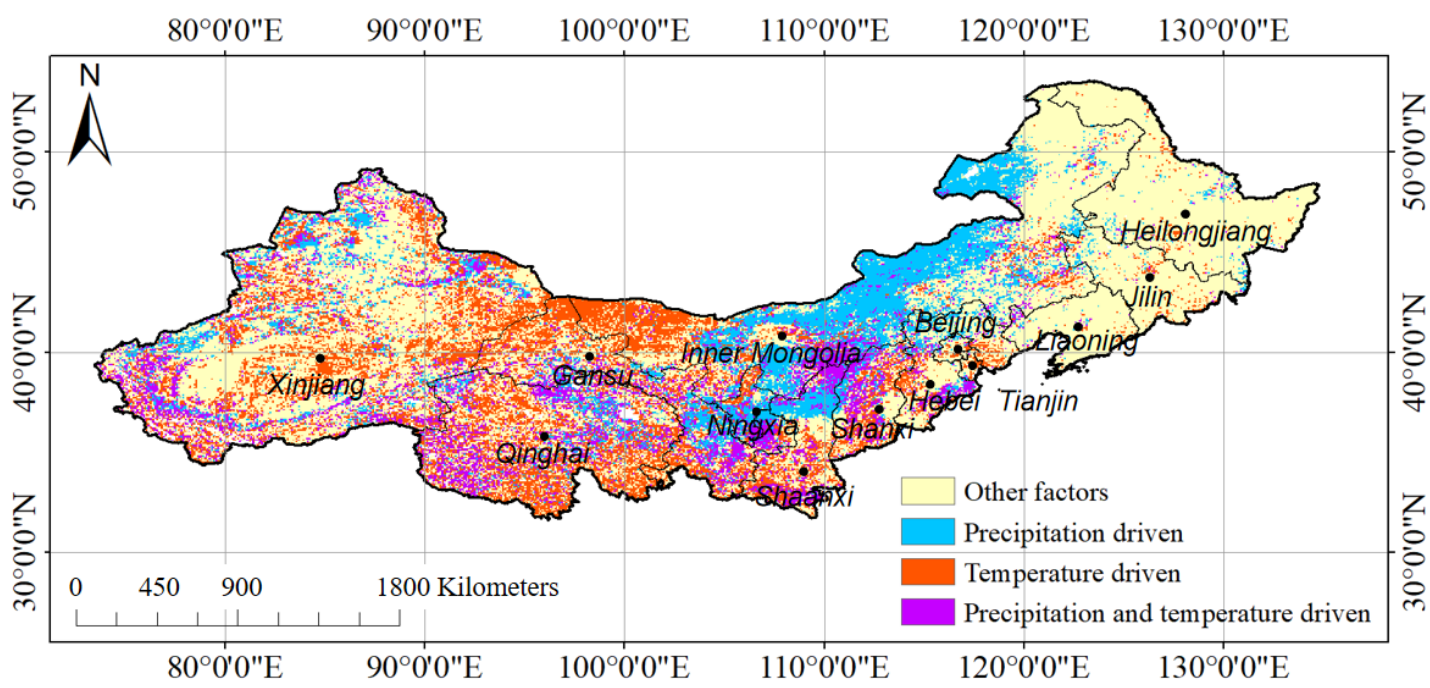

Figure 5. Distribution of the four NDVI driver types for northern China.

For quantitative analysis of NDVI change caused by four dominant drivers, we combined the NDVI change (Figure 4) with the spatial distribution of the four dominant driver types (Figure 5) to find improved and degraded NDVI regions by the four drivers. We calculated the regional average of NDVI change for the improved and degraded NDVI regions affected by the different drivers with the zonal statistics tool in ArcMap. In the NDVI improved area, temperature, precipitation, and a combination of precipitation and temperature was $0.0076,0.0051$, and 0.0066 year $^{-1}$, respectively. There was an improved NDVI of 0.0059 year $^{-1}$ in the area with other effects. In the NDVI degradation area of northern China, temperature led to a decrease of NDVI at a rate of -0.0050 year- $^{-1}$ and precipitation led to a decrease of NDVI at a rate of -0.0028 year- $^{-1}$. A combination of precipitation and temperature caused reduction of NDVI of 0.0033 year $^{-1}$. There was a decrease of NDVI by 0.0045 year $^{-1}$ in the area with other effects.

To study effects of climate change on NDVI, we calculated the trend of annual average temperature (T) and annual total precipitation (P) in northern China during 1982-2018, shown in Figures 6 and 7, respectively. Figure 6 shows that the annual average temperature increased in most of the investigated area, expect for the central Xinjiang province. Figure 7 indicates that the increasing rate of annual total precipitation in the increasing precipitation area, $0-2 \mathrm{~mm} / \mathrm{year}$, was lower than the decreasing rate for that in the decreasing precipitation area, $0-6 \mathrm{~mm} / \mathrm{year}$. The correlation between NDVI and T, NDVI and P was obtained to explain how P and T affect NDVI. As shown in Figure 8, NDVI has positive correlation with precipitation in $96 \%$ of precipitation 
driven areas. The area where NDVI is negatively related to temperature accounts for $59 \%$ of temperature dominantly driven area and is mainly distributed in the south of the investigated area. However, in $41 \%$ of temperature driven areas, the NDVI increases with increasing temperature.

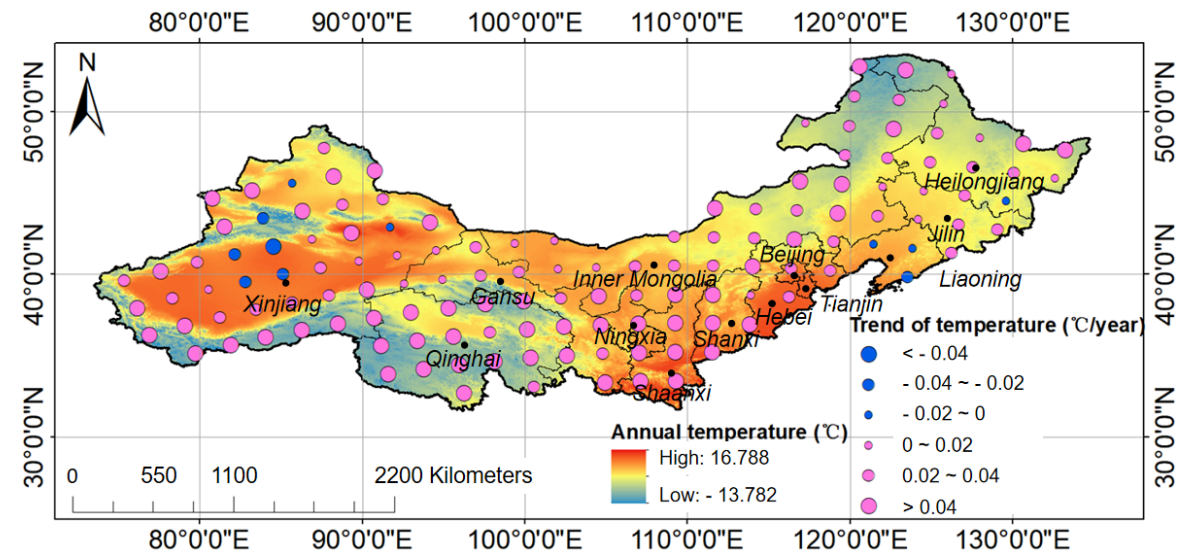

Figure 6. Distribution of annual average temperature and its trend in 1982-2018.

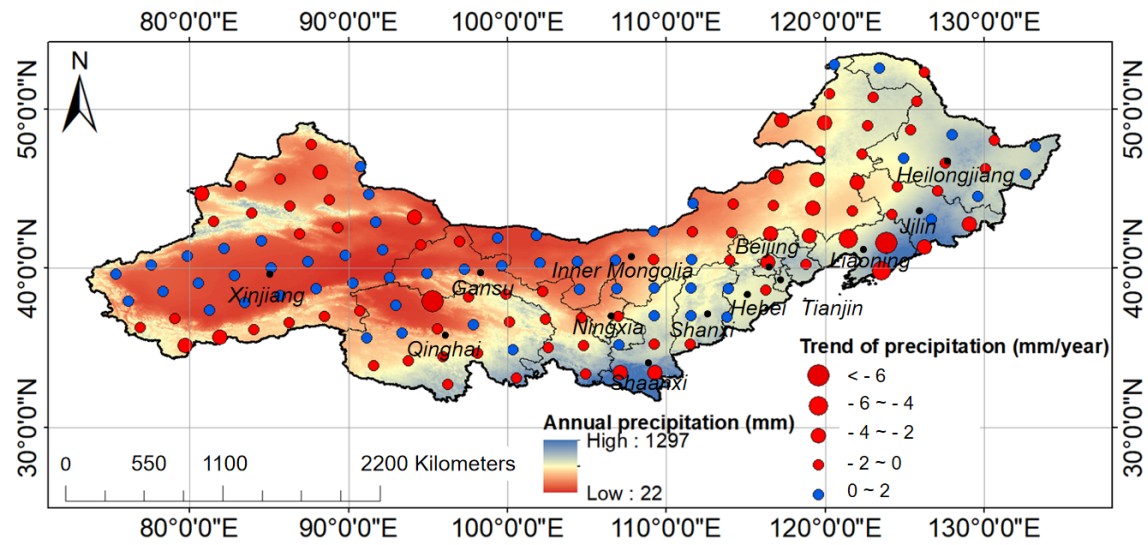

Figure 7. Distribution of annual total precipitation and its trend in 1982-2018.

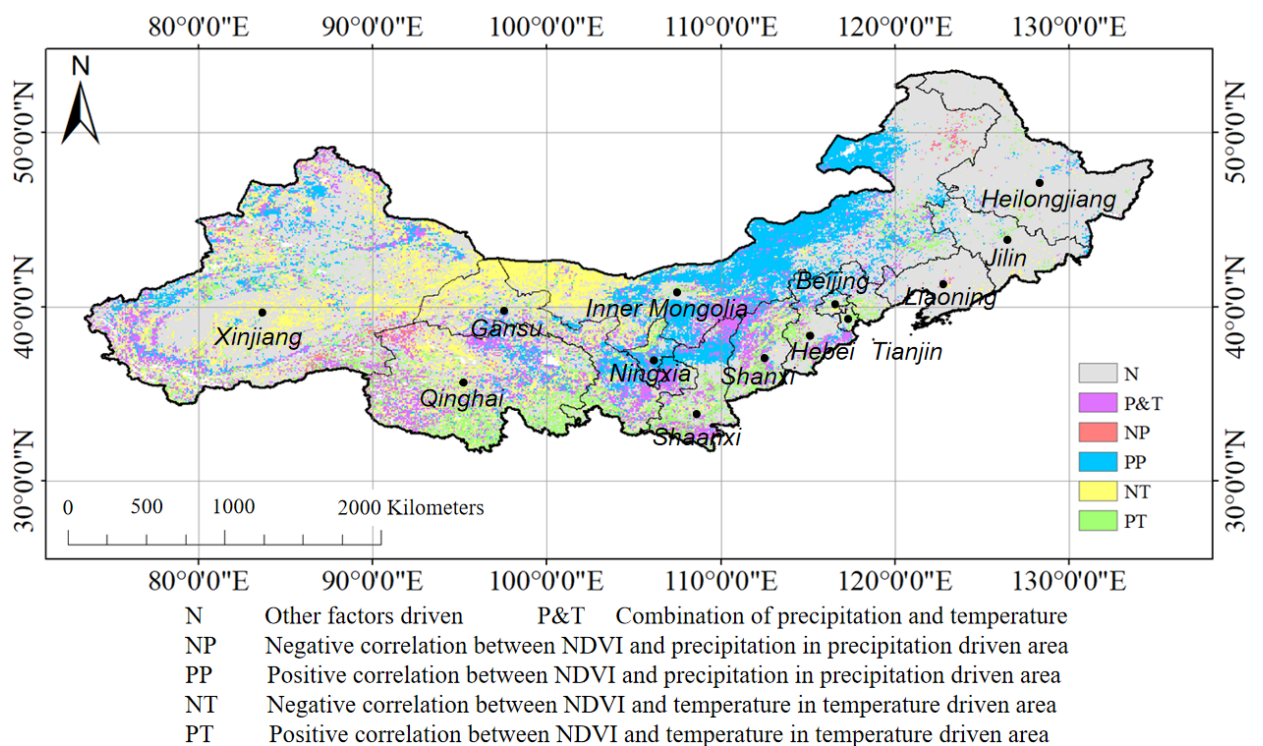

Figure 8. Distribution of the four NDVI driver types and the relationship between NDVI and precipitation/temperature for northern China.

The reasons for different effects of temperature and precipitation on NDVI change are likely complex. The geographical position leads to different climate conditions. Climate determines the 
distribution of temperature and precipitation (Figures 6 and 7), which are the most important limitations for vegetation growth [32]. Figures 9 and 10 show the distribution of different vegetation types and the land use map in the northern China. Du et al. [31] illustrated that the restrictive effect of moisture to vegetation growth is evident in areas with an annual precipitation of less than 400 $\mathrm{mm}$. In the southeast part of the study area, precipitation is more than $400 \mathrm{~mm}$ per year (Figure 7). Consequently, precipitation is not a limiting factor for NDVI increase in this area. Although the rising temperature (Figure 6) leads to the increase of evaporation, precipitation is enough to provide water for vegetation in this area. Besides, the main vegetation is cold temperate coniferous forest (Ii), temperate coniferous and deciduous broadleaf mixed forest (IIi and IIii), and warm temperate deciduous broadleaf forest (IIIi and IIIii) in the region (Figure 9), with NDVI that is not sensitive to climate change [33]. Except for forests, the main land use type in the area is cropland (Figure 10), which has been greatly interfered with by humans, such as reforestation, management, and irrigation. Thus, precipitation and temperature are not the main drivers for NDVI increasing in the southeast part in northern China.

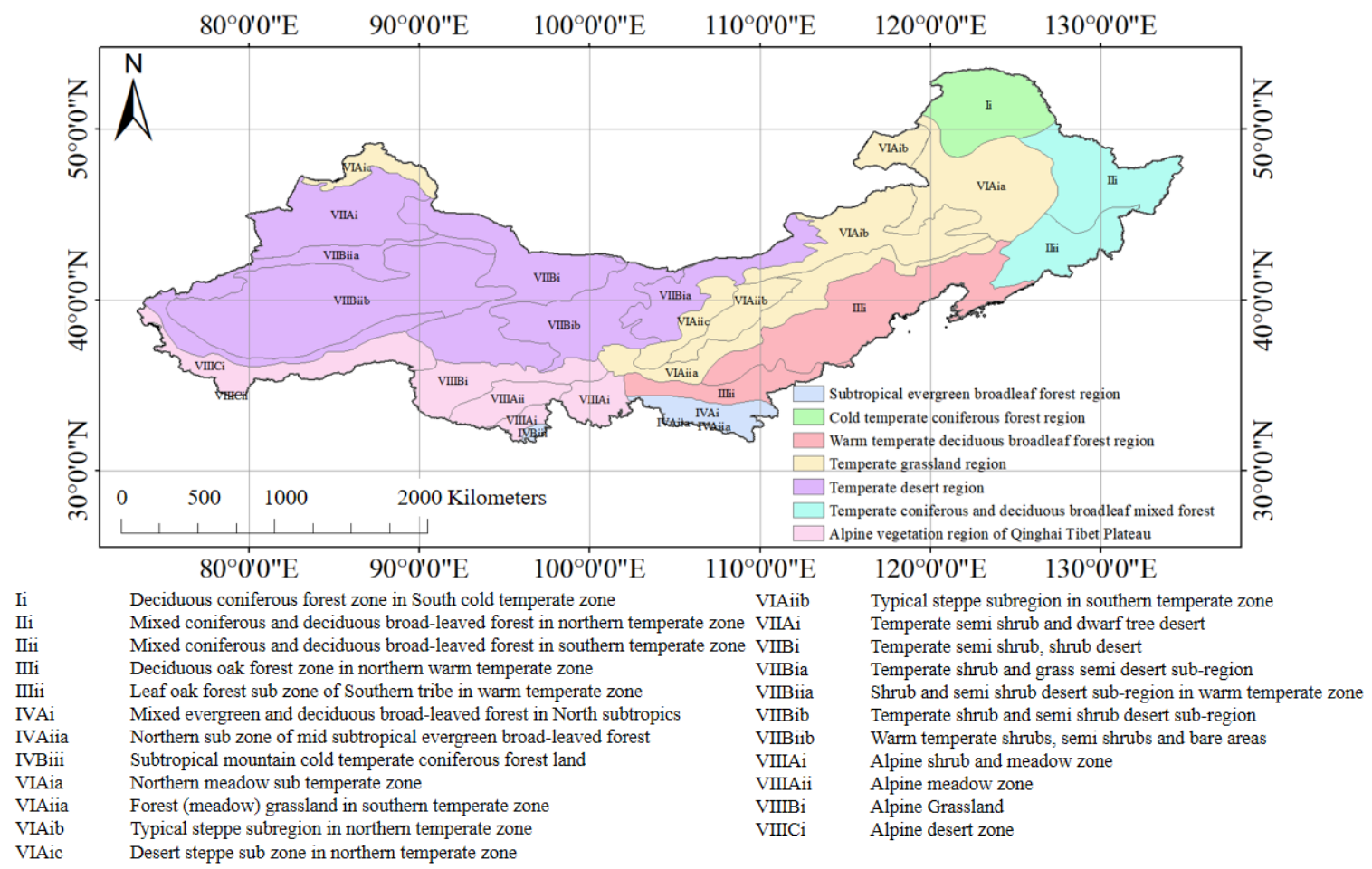

Figure 9. Vegetation regionalization in northern China.

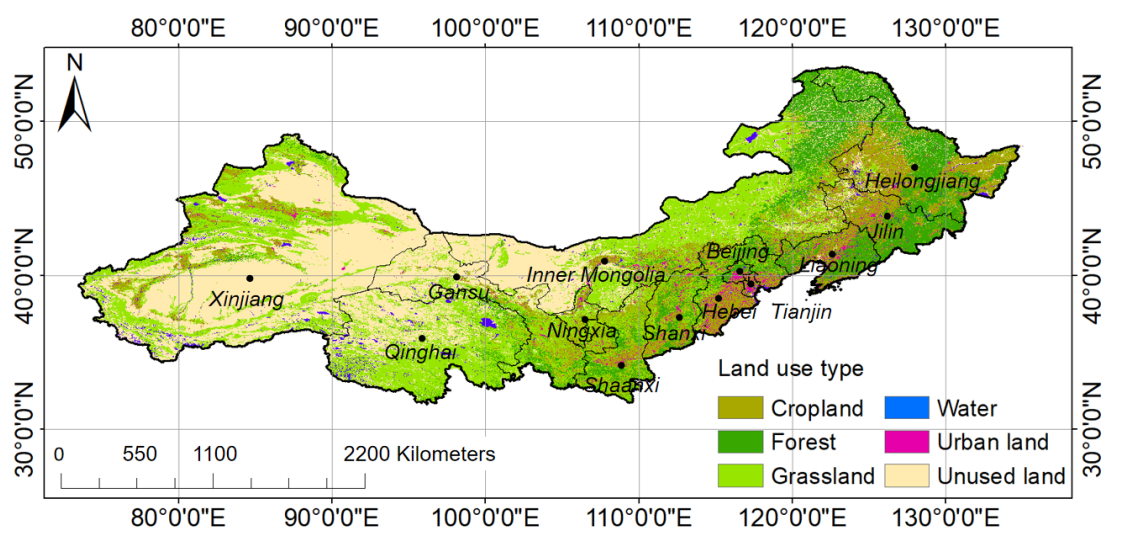

Figure 10. Land use map of northern China.

According to Figures 8 and 9, precipitation was the dominant driver of NDVI change and positively related to NDVI in the subregion VIAiia, VIAiic, VIAiib, VIAib of temperate grassland 
region, and VIIBiia of temperate desert region. The annual precipitation is between 200 and $400 \mathrm{~mm}$ and the average annual temperature is between 15 and $20^{\circ} \mathrm{C}$ [28]. Figure 10 shows that the main land use is grassland in the area. Vegetation growth and water use of herbaceous plants strongly differ from other vegetation types in drylands due to the different root distribution. Due to appropriate temperature for the growth of herbaceous plants in the region, the greenness of grassland has a strong and fast response to precipitation rather than temperature [34]. Combining Figures 6-9, we analyzed the response of NDVI to changing temperature and precipitation in the regions where temperature or precipitation is the single dominant driver for NDVI change (Figure 11). The reduction of NDVI in VIAiia, VIAiic, VIAiib, and VIAib was caused by decreasing precipitation, as shown in Figure 7. Meanwhile increasing precipitation in VIIBiia led to the improvement of NDVI (Figure 11).

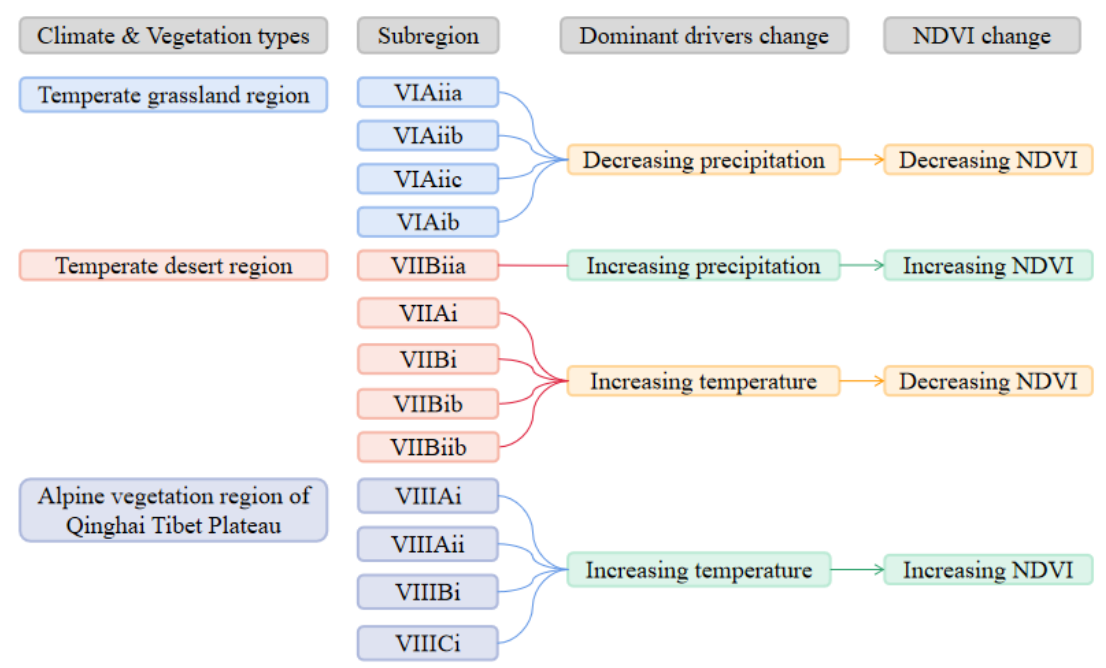

Figure 11. Response of NDVI to change of temperature and precipitation

In the alpine vegetation region of Qinghai Tibet Plateau, NDVI increased with increasing temperature. Vegetation growth contains two processes, photosynthesis and respiration, which are closely linked to temperature. In the alpine vegetation region of Qinghai Tibet Plateau, the annual average temperature is lower than $0{ }^{\circ} \mathrm{C}$, which limits the growth of alpine vegetation (including alpine grass, meadow, and shrub) by low temperature $\left(7^{\circ} \mathrm{C}\right)$ stress [35]. Warming in the area creates a more suitable environment for vegetation growth. In summary, the improvement of NDVI is driven by increasing temperature despite the change of precipitation (Figure 11).

In the subregion VIIBiib, VIIBib, VIIAi, and VIIBi of temperate desert regions (Figure 9), the NDVI is negatively related with temperature. Under small precipitation, vegetation growth exhibits stronger correlation with temperature. Warming reduces the air humidity and increases soil water evaporation, which causes shortage of water for vegetation growth [36]. Although, there was increasing precipitation in part of this area, the increasing precipitation, which is between 0 and 2 $\mathrm{mm}$ /year (Figure 7), is not enough for increasing evaporation caused by global warming. With a large proportion of unused land in the area, there is no significant change for NDVI due to the coarse resolution of NDVI data we used (Figure 11).

There are some regions where the dominant driver of NDVI change is the combination of precipitation and temperature. With increasing temperature, the NDVI increased due to increasing activity of enzymes [34]. Meanwhile, precipitation in these regions increased slightly (Figure 7), and provided water for vegetation growth, thus led to the improvement of NDVI.

\subsection{Response of NDVI Change to Reforestation}

From 1982 to 2018, the Chinese government implemented reforestation programs in northern China, such as Beijing-Tianjin-Hebei Sandstorm Source Control Project, Three-North Shelter-forest Project, and Green for Grain Project. We studied the afforested areas in each province of northern 
China (Figure 12) and found that total reforestation area is about $960,000 \mathrm{~km}^{2}$. Especially Inner Mongolia, Shaanxi, Hebei, and Shanxi provinces contain more than $100,000 \mathrm{~km}^{2}$ afforested area in each province. Figure 8 shows that the correlation between NDVI time series and cumulative reforestation area varies from 0.104 to 0.905 depending on province. The NDVI has been greatly affected by reforestation in central north China with a correlation larger than $0.80(p<0.01)$, including Shaanxi, Shanxi, and Hebei provinces. Reforestation has improved NDVI in the northeastern and part of northwestern China with a correlation between 0.60 and $0.8(p<0.01)$, including Liaoning, Jilin, Heilongjiang, Ningxia, Gansu, and Qinghai provinces. However, reforestation did not have significant effects on NDVI with a low correlation in Xinjiang and Inner Mongolia $(p>0.01)$.
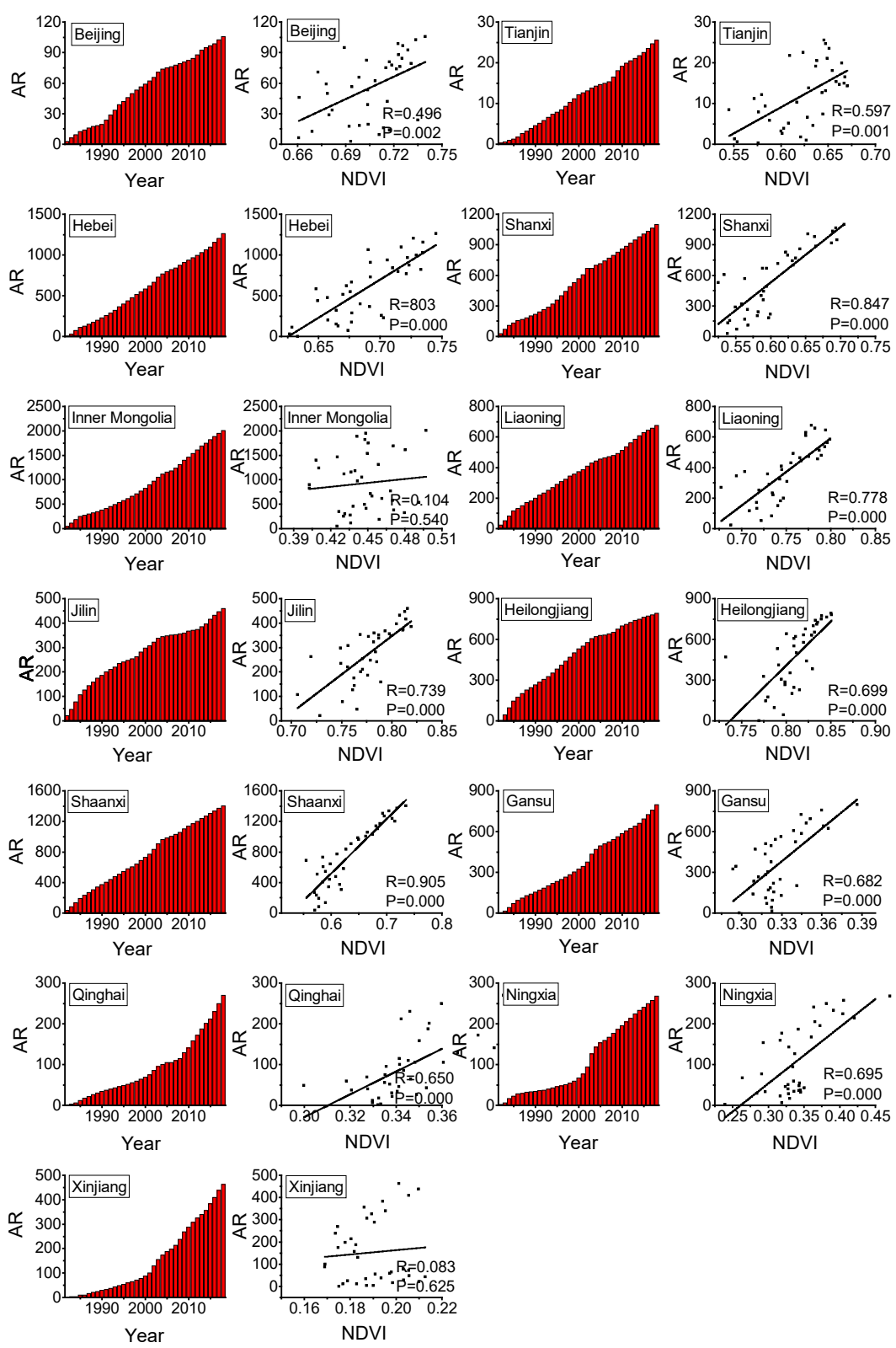

Figure 12. Accumulated reforestation area for different provinces in northern China and its relationship with regional average NDVI from 1982 to 2018 (AR represents the accumulated reforestation area, and the unit is $100 \mathrm{~km}^{2}$; NDVI represents the regional average NDVI for provinces; $\mathrm{R}$ is the correlation coefficient; $\mathrm{P}$ presents the significance of the linear relationship).

There are several factors affecting successful reforestation, including soil properties, climate, reforestation technologies, plant diseases, and insect pests [37]. The significant correlation between 
reforestation area and NDVI time series for Hebei, Shanxi, and Shaanxi provinces depends on massive reforestation programs. This includes reforestation of $10,000 \mathrm{~km}^{2}$ and returning farmland to forests in favorable climate. The three provinces belong to the semiarid and subhumid areas [38], in which the water supply for vegetation growth is sufficient with appropriate selection of plant species and water management. There was lower correlation between reforestation area and NDVI time series for northeastern China, including Heilongjiang, Jilin, and Liaoning provinces than that for Hebei, Shanxi, and Shaanxi provinces. This is due to the fact that climate is suitable for the reforestation of coniferous forest, however, the forest area declined from $36.1 \cdot 10^{4}$ to $33.7 \cdot 10^{4} \mathrm{~km}^{2}$ from 1980 to 2018. Although Chinese authorities have continued reforestation in this area, forest fires in 1987 [39] led to forest degradation [40,41]. In addition, northeastern China is the national granary with vast and fertile black earth [42]. Thus, reforestation area competes with cropland. Drought and soil salinization restrict plant species of reforestation of herbs, shrubs, arbor in Ningxia, Gansu, and Qinghai provinces $[43,44]$. This results in a lower correlation between reforestation area and NDVI time series.

The low correlation was found between reforestation area and NDVI time series for Beijing and Tianjin, and insignificant correlation between reforestation area and NDVI time series for Inner Mongolia and Xinjiang. Urban areas of Beijing and Tianjin have expanded quickly due to rapid economic development, which affects the contribution of reforestation to NDVI improvement [23]. In Inner Mongolia and Xinjiang, the harsh environment, such as low rainfall, low air humidity, low soil moisture, depleted soil, and occurrence of sand dust storm have reduced the success rate of reforestation [45].

Other human activities also promote the increase of NDVI. Except reforestation, forest protection and proper management also increase NDVI $[9,46]$. Rational utilization of cropland, such as crop rotation, intercropping and residue remaining, not only protects soil from erosion [47-49] and increases soil properties [50-52], but also increases the crop yield and NDVI for cropland $[53,54]$. With improvement of economy, residents pay more attention to the quality of life, and in turn, concern about urban greening increases NDVI for urban areas $[12,55]$.

\section{Conclusions}

The research studied the spatiotemporal variation of NDVI in northern China and its drivers, and explored the effects of different drivers on NDVI. The study concludes that NDVI increased at a rate of 0.001 year $^{-1}$ from 1982 to 2018 . About $36.1 \%$ of the total area corresponded to significant improvement of NDVI, and $9.7 \%$ of the total area faced significant degradation of NDVI. The area that is dominated by precipitation $(\mathrm{P})$, temperature $(\mathrm{T})$, a combination of precipitation and temperature (P\&T), and other factors $(\mathrm{N})$ accounted for $14.4 \%, 20.2 \%, 11.6 \%$, and $53.8 \%$ respectively.

Precipitation is the dominant driver of NDVI change and positively related to NDVI in the subregion VIAiia, VIAiic, VIAiib, and VIAib in temperate grassland regions, and VIIBiia of temperate desert regions. The regions where NDVI is positively dominated by $\mathrm{T}$ are alpine vegetation region of Qinghai Tibet Plateau. NDVI is negatively dominated by $\mathrm{T}$ in the subregion VIIBiib, VIIBib, VIIAi, and VIIBi in temperate desert regions.

Human activity affects the distribution of NDVI driven factors by reforestation. NDVI had significant linear relationship with reforestation area in Shaanxi, Shanxi, and Hebei provinces. Afforestation did not have significant effects on NDVI with a low correlation in Xinjiang and Inner Mongolia.

We studied the interannual change of NDVI. Future studies should consider other metrics (e.g., phenometrics) for monitoring the annual variation of vegetation. Meanwhile more accurate vegetation distribution is needed to explore the response of NDVI to climate change in the future. Besides, the methods for quantitative analysis on the contribution of climate change and human activity on NDVI change should be explored in the future.

Author Contributions: X.L. carried out the study with the help from J.N. and the fund from X.Y., analyzed data, and wrote the initial draft with help from J.N., R.B., L.Z. and X.C. All authors have read and agreed to the published version of the manuscript. 
Funding: This research was funded by the National key research and development project, grant number 2019YFF0303203.

Conflicts of Interest: The authors declare no conflict of interest.

\section{References}

1. Ning, T.T.; Liu, W.Z.; Liu, W.; Song, X.Q. NDVI variation and its responses to climate change on the northern loess plateau of china from 1998 to 2012. Adv. Meteorol. 2015, 2015, 725427.

2. Homolova, L. Imaging Spectroscopy for Ecological Analysis in Forest and Grassland Ecosystems; Wageningen University: Wageningen, The Netherlands, 2014.

3. Godínez-Alvarez, H.; Herrick, J.E.; Mattocks, M.; Toledo, D.; Van Zee, J. Comparison of three vegetation monitoring methods: Their relative utility for ecological assessment and monitoring. Ecol. Indic. 2009, 9, 1001-1008.

4. Wang, S.; Xu, X.; Shrestha, N.; Zimmermann, N.E.; Wang, Z. Response of spatial vegetation distribution in china to climate changes since the last glacial maximum (lgm). PLOS ONE 2017, 12, e0175742.

5. Fu, B.; Li, S.; Yu, X.; Yang, P.; Yu, G.; Feng, R.; Zhuang, X. Chinese ecosystem research network: Progress and perspectives. Ecol. Complex. 2010, 7, 225-233.

6. Yang, H. China's natural forest protection program: Progress and impacts. For. Chron. 2017, 93, $113-117$.

7. Li, S.S.; Yang, S.N.; Liu, X.F.; Liu, Y.X.; Shi, M.M. NDVI-Based Analysis on the Influence of Climate Change and Human Activities on Vegetation Restoration in the Shaanxi-Gansu-Ningxia Region, Central China. Remote Sens. 2015, 7, 11163-11182.

8. Reid, S.L.; Walker, J.L.; Schaaf, A. Using multi-spectral Landsat imagery examine forest health trend at Fort Benning, Georgia. In Proceedings of the 18th Biennial Southern Silvicultural Research Conference; U.S. Department of Agriculture Forest Service, Southern Research Station: Asheville, NC, USA, 2016; pp. 601603.

9. Esau, I.; Miles, V.V.; Davy, R.; Miles, M.W.; Kurchatova, A. Trends in normalized difference vegetation index (NDVI) associated with urban development in northern west Siberia. Atmos. Chem. Phys. 2016, 16, 9563-9577.

10. Shi, M.Y.; Qi, J.G.; Yin, R.S. Has China's Natural Forest Protection Program Protected Forests? -Heilongjiang's Experience. Forests 2016, 7, 218.

11. Eastman, J.R.; Sangermano, F.; Machado, E.A.; Rogan, J.; Anyamba, A. Global Trends in Seasonality of Normalized Difference Vegetation Index (NDVI), 1982-2011. Remote Sens. 2013, 5, 4799-4811.

12. Wu, D.H.; Wu, H.; Zhao, X.; Zhou, T.; Tang, B.J.; Zhao, W.Q.; Jia, K. Evaluation of Spatiotemporal Variations of Global Fractional Vegetation Cover Based on GIMMS NDVI Data from 1982 to 2011. Remote Sens. 2014, 6, 4217-4239.

13. Liu, Q.; Yang, Z.; Han, F.; Wang, Z.; Wang, C. NDVI-based vegetation dynamics and their response to recent climate change: A case study in the Tianshan mountains, China. Environ. Earth Sci. 2016, 75, 1189.

14. Wang, F.; An, P.; Huang, C.; Zhang, Z.; Hao, J. Is afforestation-induced land use change the main contributor to vegetation dynamics in the semiarid region of north China? Ecol. Indic. 2018, 88, $282-291$.

15. Zhang, X.Y.; Friedl, M.A.; Schaaf, C.B.; Strahler, A.H. Climate controls on vegetation phenological patterns in northern mid- and high latitudes inferred from MODIS data. Glob. Chang. Biol. 2004, 10, 1133-1145.

16. Guo, J.; Hu, Y.; Xiong, Z.; Yan, X.; Bu, R. Spatiotemporal variations of growing-season NDVI associated with climate change in northeastern china's permafrost zone. Pol. J. Environ. Stud. 2017, 26, 1521-1530.

17. Cao, R.; Jiang, W.; Yuan, L.; Wang, W.; Lv, Z.; Chen, Z. Inter-annual variations in vegetation and their response to climatic factors in the upper catchments of the Yellow River from 2000 to 2010. J. Geogr. Sci. 2014, 24, 963-979.

18. Hou, M.T.; Zhao, H.Y.; Wang, Z.; Yan, X.D. Vegetation responses to climate change by using the satellite-derived normalized difference vegetation index: A review. Clim. Environ. Res. 2013, 18, 353-364. [In Chinese with English Abstract].

19. Xu, Y.; Yang, J.; Chen, Y. Ndvi-based vegetation responses to climate change in an arid area of china. Theor. Appl. Climatol. 2016, 126, 213-222.

20. Wang, H.; Liu, G.H.; Li, Z.S.; Ye, X.; Fu, B.J.; Lv, Y.H. Impacts of drought and human activity on vegetation growth in the grain for green program region, China. Chin. Geogr. Sci. 2018, 28, 470-481.

21. Huang, Y.; Wang, N.A.; He, T.; Chen, H.; Zhao, L. Historical desertification of the mu us desert, northern china: A multidisciplinary study. Geomorphology 2009, 110, 108-117. 
22. Fei, J.; Zhang, D.D.; Lee, H.F.; Hou, Y.J. Extreme dust storm disaster in northern China in AD 1523. Asian Geogr. 2012, 29, 77-87.

23. Zhou, J.; Zhang, Z.; Sun, G.; Fang, X.; Zha, T.; McNulty, S.; Chen, J.; Jin, Y.; Noormets, A. Response of ecosystem carbon fluxes to drought events in a poplar plantation in northern China. Forest Ecol. Manag. 2013, 300, 33-42.

24. Wang, Q.; Zhang, B.; Dai, S.P.; Zou, Y.; Ma, Z.H. Dynamic changes in vegetation coverage in the Three-North Shelter Forest program based on GIMMS AVHRR NDVI. Resource Sci. 2011, 33, 1613-1620.

25. Xin, Z.; Xu, J.; Zheng, W. Spatiotemporal variations of vegetation cover on the Chinese loess plateau (1981-2006): Impacts of climate changes and human activities. Sci. China Ser. D Earth Sci. 2008, 51, 67-78.

26. Kenett, D.Y.; Huang, X.; Vodenska, I.; Havlin, S.; Stanley, H.E. Partial correlation analysis: Applications for financial markets. Quant. Financ. 2015, 15, 569-578.

27. Liu, X.F.; Zhu, X.F.; Li, S.S. Changes in growing season vegetation and their associated driving forces in China during 2001 2012. Remote Sens. 2015, 7, 15517-15535.

28. Song, Y.I.; Ma, M.G. A statistical analysis of the relationship between climatic factors and the normalized difference vegetation index in China. Int. J. Remote Sens. 2011, 32, 3947-3965.

29. Elsner, J.B.; Tsonis, A.A.; Jagger, T.H. High-Frequency Variability in Hurricane Power Dissipation and Its Relationship to Global Temperature. Bull. Am. Meteorol. Soc. 2006, 87, 763-768.

30. Wang, Y.C.; Sun, Y.L.; Wang, Z.L. Spatial-Temporal Change in Vegetation Cover and Climate Factor Drivers of Variation in the Haihe River Basin 1998-2011. Resour. Ence 2014, 36, 594-602.

31. Du, J.Q.; Jiaerheng, A.; Zhao, C.X.; Fang, G.L.; Fang, S.F. Dynamic changes in vegetation NDVI from 1982 to 2012 and its responses to climate change and human activities in Xinjiang, China. J. Appl. Ecol. 2015, 26, 3567-3578.

32. Wang, Z.M.; Guo, Z.X.; Song, K.S.; Luo, L.; Zhang, B.; Liu, D.W.; Huang, N.; Ren, C.Y. Responses of vegetation NDVI in Northeast China to climate chang. Chin. J. Ecol. 2009, 28, 1041-1048.

33. Zhao, X.; Tan, K.; Zhao, S.; Fang, J. Changing climate affects vegetation growth in the arid region of the northwestern china. J. Arid Environ. 2011, 75, 946-952.

34. Ashraf, M.; Harris, P.J.C. Photosynthesis under stressful environments: An overview. Photosynthetica 2013, 51, 163-190.

35. Du, J.; Quan, Z.; Fang, S.; Liu, C.; Fu, Q. Spatiotemporal changes in vegetation coverage and its causes in china since the Chinese economic reform. Environ. Sci. Pollut. Res. 2019, 27, 1144-1159.

36. Chang, J.; Tian, J.; Zhang, Z.; Chen, X.; Chen, Y.; Chen, S.; Duan, Z. Changes of grassland rain use efficiency and ndvi in northwestern china from 1982 to 2013 and its response to climate change. Water 2018, 10, 1689.

37. Shi, F.; Zhao, C.; Zhou, X.; Li, X. Spatial variations of climate-driven trends of water vapor pressure and relative humidity in northwest china. Asia-Pac. J. Atmos. Sci. 2019, 55, 221-231.

38. Hunt, E.R.; Kelly, R.D.; Smith, W.K.; Fahnestock, J.T.; Welker, J.M.; Reiners, W.A. Estimation of carbon sequestration by combining remote sensing and net ecosystem exchange data for northern mixed-grass prairie and sagebrush-steppe ecosystems. Environ. Manag. 2004, 33, 432-441.

39. Frédéric, H.; Alina, G.B.; Braconnot, P.; Jean-Louis, D.; Aboul-Khadre, T.; Rio, C. Air moisture control on ocean surface temperature, hidden key to the warm bias enigma. Geophys. Res. Lett. 2015, 42, 10-885.

40. Wu, D.; Fang, S.; Li, X.; He, D.; Zhu, Y.; Yang, Z.; Xu, J.; Wu, Y. Spatial-temporal variation in irrigation water requirement for the winter wheat-summer maize rotation system since the 1980s on the north China plain. Agric. Water Manag. 2019, 214, 78-86.

41. Zeng, Y.; Liu, T.; Zhou, X.B.; Sun, Q.M.; Han, Z.Q.; Liu, K. Effects of climate change on plant composition and diversity in the Gurbantunggut desert of northwestern China. Ecol. Res. 2016, 31, 427-439.

42. Mariano, M.H.; Ruben, D.S.; Laura, T.; Wainwright, J. Assessing vegetation structure and ANPP dynamics in a grassland-shrubland Chihuahuan ecotone using NDVI-rainfall relationships. Biogeosciences 2015, 12, 2907-2925.

43. Zhang, L.X.; Liu, G.S.; Liu, E.P.; Zhang, J. Discussion on Influencing Factors of afforestation success or failure. Technol. Living 2010, 23, 4-30.

44. Xu, X.L.; Zhang, Y.Q. China Meteorological Background Data Set. Data Registration and Publishing System of Data Center of Resources and Environmental Sciences, Chinese Academy of Sciences. 2017. Available online: http://www.resdc.cn/DOI (accessed on 31 December 2019). 
45. Wang, L.; Fu, Q. Soil quality assessment of vegetation restoration after a large forest fire in Daxing'anling, northeast china. Can. J. Soil Sci. 2020, 100, 162-174.

46. Riebau, A.R.; Qu, J.J. Application of Remote Sensing and GIS for Analysis of Forest Fire Risk and Assessment of Forest Degradation. In Natural Disasters and Extreme Events in Agriculture; Springer: Berlin/Heidelberg, Germany, 2005; pp. 335-350.

47. Matricardi EA, T.; Skole, D.L.; Pedlowski, M.A.; Chomentowski, W.; Fernandes, L.C. Assessment of tropical forest degradation by selective logging and fire using Landsat imagery. Remote Sens. Environ. 2010, 114, 1117-1129.

48. Liu, C. Soil carbon pool in northeast plain of china and its relations between the soil properties. Quat. Res. 2013, 33, 986-994.

49. Zhang, P.P.; Shao, M.A.; Zhang, X.C. Spatial pattern of plant species diversity and the influencing factors in a Gobi Desert within the Heihe River basin, northwest China. J. Arid Land 2017, 9, 391-393.

50. Huo, C.; Gao, Y.; Qian, H.; Yang, J. Application of analytic hierarchy process on the study of soil salinization in the Northern Yinchuan Plain, China. In Proceedings of the 2015 International Conference on Materials, Environmental and Biological Engineering, Guilin, China, 28-30 March 2015; pp. 484-487.

51. Li, S.D.; Liu, X. Study on regional model of return of farmland to afforestation in Loess Plateau area. Prot. Forest Sci. Technol. 2004, 4, 3-7.

52. Wang, G.; Han, L.; Zhang, Y. Temporal variation and spatial distribution of NDVI in northeastern China. J. Beijing Forest. Univ. 2012, 34, 86-91.

53. Kinderiene, I.; Karcauskiene, D. Effects of different crop rotations on soil erosion and nutrient losses under natural rainfall conditions in western Lithuania. Acta Agric. Scand. Sect. B Soil Plant Sci. 2012, 62, $199-205$.

54. Rakkar, M.K.; Blanco-Canqui, H.; Tatarko, J. Predicting soil wind erosion potential under different corn residue management scenarios in the central Great Plains. Geoderma 2019, 353, 25-34.

55. Han, F.U.; Fenli, Z.; Chao, Q.; Lei, W. Effects of crop rotation on preventing hillslope soil erosion and its c factor's variation in thin layer Mollisol region of the northeast China. J. Soil Water Conserv. 2019, 28, 14-19.

Publisher's Note: MDPI stays neutral with regard to jurisdictional claims in published maps and institutional affiliations.

(C) 2020 by the authors. Licensee MDPI, Basel, Switzerland. This article is an open access article distributed under the terms and conditions of the Creative Commons Attribution (CC BY) license (http://creativecommons.org/licenses/by/4.0/). 